\title{
Incontinencia pigmenti en madre e hija. Relato de caso clínico
}

\author{
M ${ }^{\mathrm{a}}$ LEONOR ENEI G. ${ }^{1}$, IVÁN ORELLANA A. ${ }^{2}$, XIMENA VARGAS R. ${ }^{3}$, \\ RENÉ SALAZAR C. ${ }^{4}$, FRANCISCO PASCHOAL ${ }^{5}$ \\ 1. Especialista en Dermatología. Profesor Asistente en Dermatología. Universidad del Mar. Iquique. Chile. \\ 2. Especialista en Pediatría. Clínica privada. Iquique. Chile. \\ 3. Dermatólogo. Jefe Servicio de Dermatología Hospital Clínico San Borja Arriarán Santiago Chile. \\ 4. Alumno de $6^{\circ}$ año de Medicina. Universidad del Mar. Iquique. Chile. \\ 5. Dermatólogo. Profesor Asistente en Dermatología. Facultad de Medicina ABC. Sao Paulo Brasil.
}

\begin{abstract}
Mother and daughter incontinentia pigmenti. Case report

Incontinentia pigmenti (IP) is a rare genodermatosis linked to the $\mathrm{X}$ chromosome. It affects variably all tissues derives from neuroecthoderm such as skin, hair, nails, eyes and central nervous system. Early diagnosis allows the study of eventual multisystem involvement. Clinical case: We describe a 6 m.o. girl, controlled from the first week of life for a dermatological feature characterized by linear lesions, which were vesicular, then verrucous, and finally hyperpigmented. IP diagnostic family, determined by maternal history of similar lesions. (Key words: X-linked dominant; incontinentia pigmenti; genodermatosis; neurocutaneous syndromes). Rev Chil Pediatr 2011; 82 (3): 225-230
\end{abstract}

\section{RESUMEN}

La incontinentia pigmenti (IP) es una genodermatosis rara ligada al cromosoma X. Afecta en forma variable a los tejidos derivados del neuroectodermo, como la piel, pelos, uñas, ojos y el sistema nervioso central. Su conocimiento y diagnóstico precoz permite estudiar un eventual compromiso multisistémico. Describimos el caso de una niña de 6 meses de edad, controlada desde la primera semana de vida por un cuadro dermatológico caracterizado por lesiones lineales vesiculosas, verrucosas y posteriormente hiperpigmentadas. Se plantea el diagnóstico de IP familiar, determinado por antecedentes maternos de lesiones similares.

(Palabras clave: Dominante ligado al X; incontinencia pigmenti; genodermatosis; síndromes neurocutáneos). Rev Chil Pediatr 2011; 82 (3): 225-230

Trabajo recibido el 06 de marzo de 2011, devuelto para corregir el 12 de abril de 2011, segunda versión el 25 de abril de 2011, aceptado para publicación el 02 de mayo de 2011.

Correspondencia a:

Dra. Ma Leonor Enei G.

E-mail: leonorenei@vtr.net 


\section{Introducción}

La incontinencia pigmenti (IP) es una genodermatosis de escasa frecuencia, ligada en forma dominante al cromosoma X. Las manifestaciones cutáneas están siempre presentes y se dividen en cuatro fases distintas: vésico ampollosa, verrucosa, hiperpigmentadas y finalmente una fase hipopigmentada y atrófica. Reportamos el caso clínico de una paciente que recibimos a los 7 días de vida, derivada desde pediatría por presentar desde su nacimiento un cuadro cutáneo de vesículas y ampollas. El aspecto de las lesiones, su distribución y su evolución, además del antecedente materno de lesiones similares en la infancia, nos permitió establecer el diagnóstico de IP. Resaltamos las cuatro fases cutáneas de esta enfermedad, las tres primeras en la niña y la cuarta en la madre de ésta, constituyendo así un caso de IP familiar.

\section{Caso clínico}

Recién nacida de sexo femenino, tercera hija de padres no consanguíneos, producto de término y parto eutócico. Tiene dos hermanos mayores aparentemente sanos. La madre tiene antecedentes previos de dos abortos espontáneos, que ocurrieron durante el primer trimestre de embarazo. A los 7 días de vida, la niña fue derivada para evaluación dermatológica por una erupción vesiculosa en el cuerpo, presente desde el nacimiento. Se encontró en buen estado general, afebril y se alimentaba de forma normal.
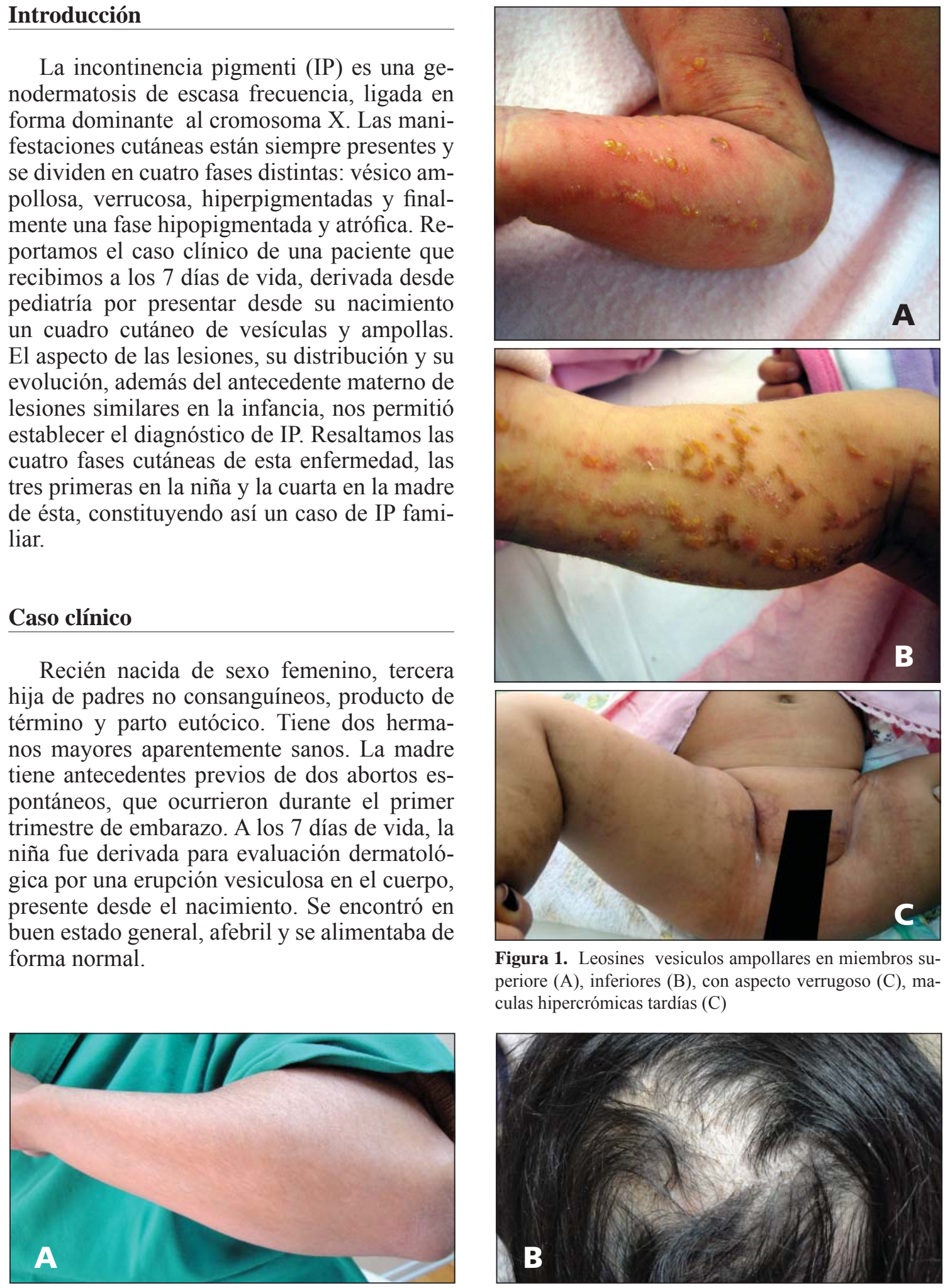

Figura 1. Leosines vesiculos ampollares en miembros superiore (A), inferiores (B), con aspecto verrugoso (C), maculas hipercrómicas tardías $(\mathrm{C})$

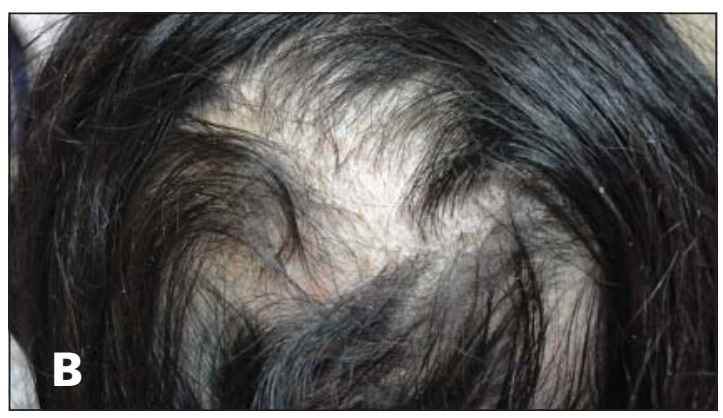

Figura 2. Lesiones de aspecto atrófico e hipocromico en edad adulta (A), alopecia en vertex de cuero cabelludo (B). 
Al examen físico se observaron vesículas y ampollas de contenido seroso y aspecto tenso, dispuestas linearmente siguiendo las líneas de Blaschko en miembros superiores (figura 1A), inferiores y tronco, la base era eritematosa, tendían a confluir y se entremezclaban con lesiones eritemato escamosas (figura 1B), de aspecto verrugoso (figura 1C). Durante las 4 semanas siguientes, la paciente desarrolló nuevas vesículas, que fueron desapareciendo en forma espontánea. Se le administraron emolientes suaves, y por un tiempo corto se aplicó hidrocortisona tópica en las áreas de eritema más acentuado. Posterior a este período aparecieron máculas hipercrómicas igualmente distribuidas siguiendo las líneas de Blaschko, pero no necesariamente en el lugar de las lesiones vesiculosas, las cuales persistían hasta el último control realizado a los 7 meses de vida. (figura 1C).

El resto del examen físico fue normal. El desarrollo pondoestatural y psicomotor resultó adecuado para la edad, y las evaluaciones neurológica y oftalmológica no presentaron alteraciones.

Un antecedente importante de destacar es que la madre refirió que al momento de su nacimiento presentó lesiones similares a las de su hija, que posteriormente evolucionaron a máculas hiperpigmentadas durante su infancia, y que fueron desapareciendo progresivamente. En la actualidad presenta zonas de piel con aspecto atrófico e hipocrómico, en miembros inferiores y antebrazos (figura 2A), dientes cónicos y alopecia en vertex de cuero cabelludo (figura 2B).

\section{Discusión}

La IP, antes conocida como Síndrome de Bloch Sulzberger, es una genodermatosis poco frecuente. Fue descrita por Garrod en 1906, y posteriormente definida por Bloch en 1926 y Sulzberger en 1928 como Incontinentia Pigmenti, basados en los hallazgos histopatológicos característicos -aunque no patognomónicos- de las lesiones cutáneas de la tercera fase de la enfermedad, en la cual se encuentra melanina libre en la dermis o dentro de los melanófagos dérmicos ${ }^{1}$.
Este trastorno se transmite en forma dominante ligada al cromosoma $\mathrm{X}$, por lo que afecta principalmente a mujeres, entre las cuales el fenotipo y severidad del cuadro clínico pueden ser extremadamente variables, lo que se explicaría por el fenómeno de Lyon o lionización, mediante el cual uno de los cromosomas X sufre inactivación al azar durante la embriogénesis temprana. Dicho proceso también determina diferentes clones de células convirtiendo a las pacientes portadoras del defecto genético en verdaderos mosaicos en relación al silenciamiento del gen anómalo².

Debido a que los hombres portan sólo un cromosoma $\mathrm{X}$, desarrollan la enfermedad en forma más severa, al igual que mujeres que presentan el defecto en forma homocigótica. En ambos casos se produce la muerte in útero. Los casos de neonatos masculinos afectados son escasos, y estarían explicados por los siguientes mecanismos: presencia de cromosoma supernumerario, con un cariotipo $47 \mathrm{XXY}$, correspondiente al síndrome de Klinefelter'; presencia de mosaicismo somático para mutación de NEMO en una sola cromátide ${ }^{4,5}$, o por la presencia de alelos hipomórficos con menos mutaciones deletéreas que producen formas leves de la enfermedad.

La mutación responsable de la IP afecta al gen NEMO (Nuclear factor-KB Essential Modulator), localizado en la porción 28 del brazo largo del cromosoma X (Xq28). Este gen codifica la subunidad regulatoria del complejo $1 \mathrm{kB}$ kinasa necesario para la activación del factor nuclear $\mathrm{KB}(\mathrm{NF} k \mathrm{~B})^{6}$, que protege a la célula contra la apoptosis y controla la transcripción de genes para la síntesis de citoquinas y quimioquinas relacionados con el sistema inmune y la morfogénesis de la piel y el esqueleto ${ }^{6}$. En el $80 \%$ de los casos esta mutación ocurre por un rearreglo genético originado por la deleción de los axones 4 al 10 del gen NEMO. Una nueva mutación fue encontrada recientemente afectando a p.Gln332X en 1 de 12 pacientes mujeres portadoras de $\mathrm{IP}^{7}$.

Debido a que este síndrome afecta a las estructuras derivadas del neuroectodermo y mesodermo, las manifestaciones clínicas abarcan alteraciones en la piel, dientes, ojos, sistema nervioso y esqueleto. 
Las lesiones cutáneas son una constante, y se caracterizan por evolucionar en cuatro estadios que se van superponiendo o sucediendo llegando incluso a desaparecer en la pubertad o vida adulta, y por distribuirseiguiendo las líneas de Blaschko. Estos estadios son:

Primera fase o vesiculosa: Se observan vesículas o ampollas sobre piel eritematosa dispuestas en forma irregular en miembros y tronco. Las lesiones aparecen al nacer o durante los primeros meses de vida y pueden persistir semanas o meses. En esta fase de la enfermedad podemos encontrar leucocitosis y eosinoflia hasta en el $70 \%$ de los casos.

Segunda fase o verrucosa: Vemos lesiones de aspecto verrucoso, compuestos por pápulas y pústulas hiperqueratósicas, formando placas lineares. Aparecen entre la $2^{\circ}$ y $8^{\circ}$ semana de vida, y desaparecen después de algunos meses.

Ambas etapas podrían pasar desapercibidas si ocurren durante la vida intrauterina.

Tercera fase o hiperpigmentada: Se caracteriza por la presencia de máculas hiperpigmentadas café o gris azuladas que siguen las líneas de Blaschko en patrones arremolinados. Se presenta entre la $12^{\circ}$ y $40^{\circ}$ semana de vida, se mantiene durante la infancia y desaparece lentamente hasta la vida adulta.

Cuarta fase o hipopigmentada: Se caracteriza por lesiones lineares hipopigmentadas y atróficas, que aparecen en la vida adulta en piel de tronco y miembros.

Los diagnósticos diferenciales que se deberían plantear ante una sospecha de IP van a depender de la etapa en la que se encuentre la enfermedad: para el estadío vesiculoso cabe plantear herpes neonatal, impétigo ampolloso por Staphylococcus aureus, mastocitosis, histiocitosis, epidermólisis ampollosa hereditaria y enfermedad ampollosa por IgA linear. Para el estadio verrucoso, se deben incluir nevus epidérmico lineal y liquen estriado. En cuanto al estadío hiperpigmentado, cabe señalar la hipermelanosis nevoide linear y en remolinos y síndrome de Naegeli-Franceschetti-Jadassohn.
Y finalmente, para el estadío hipopigmentar atrófico, se consideran la hipomelanosis de ITO y la aplasia cutis.

La histología también será diferente para cada uno de los estadios. El primer estadío presenta espongiosis con eosinófilos y formación de vesículas epidérmicas. En el segundo estadío se observa acantosis, papilomatosis irregular e hiperqueratosis, con células disqueratósicas dispersas y degeneración con vacuolización de la capa basal. En lesiones del tercer estadío encontramos melanófagos en el infiltrado inflamatorio.y melanina libre en la dermis, con ausencia o disminución de la melanina en la capa basal de la epidermis. Finalmente, en el último estadío es frecuente observar queratinocitos apoptóticos y atrofia de los folículos pilosos, con ausencia del músculo erector del pelo ${ }^{9}$.

En la IP, además de la piel, es posible ver afectados los anexos cutáneos. El cabello puede ser fino y escaso, o presentar alopecia cicatricial del vértex $(40 \% \text { de los casos) })^{1}$, como la que observamos en la madre de nuestra paciente. Las uñas podrían presentarse distróficas, e incluso desarrollar tumores queratósicos periungueales ${ }^{10}$.

El $80 \%$ de los pacientes portadores de IP presentan compromiso extracutáneo. Las alteraciones dentales se ven en el 65 a $80 \%$ de los casos, las oculares en el $35^{11}$ a $47 \%{ }^{12}$, y el sistema nervioso central en el 5 al 13\%. Estos últimos determinan el pronóstico en un paciente afectado y deben ser investigados.

Las alteraciones dentales más frecuentes son la erupción retardada, los dientes cónicos o en clavija ${ }^{13}$, y la hipodoncia.

Las alteraciones oculares pueden incluir estrabismo, cataratas, atrofia óptica y glaucoma congénito, microftalmia y vasculitis retinia$\mathrm{na}^{14}$. Cabe la posibilidad de una neovascularización de la retina rápidamente progresiva con riesgo de desprendimiento. Ante la gravedad de esta complicación se sugiere el seguimiento estrecho de todo paciente, con o sin patología retiniana, recomendándose la angiografía con fluorosecncia en aquellos que sí la presentan, para determinar así la extensión de la isquemia e inicio precoz de tratamiento con fotocoagulación $^{12}$. 
El compromiso del sistema nerviosos central suele manifestarse durante el primer año de vida, incluyendo microcefalia, retraso en el desarrollo psicomotor, espasticidad, ataxia y convulsiones ${ }^{15}$.

Cuando el sistema esquelético se encuentra afectado puede haber presencia de hemivértebras, escoleosis, espina bífida, sindacatilia y costillas supernumerarias. También han sido descritos anomalías en huesos de la cara y oí$\operatorname{dos}^{16}$.

Para realizar el diagnóstico de IP es fundamental el reconocimiento de las lesiones cutáneas. De acuerdo a lo planteado por Landy y Donnai $^{1}$, la presencia de éstas y la existencia de un familiar de primer grado afectado, constituirían criterios mayores de la enfermedad y al menos uno de ellos debe estar presente para realizar el diagnóstico de IP. Los criterios menores aluden al compromiso de los anexos y al compromiso extracutáneo, entre los que se mencionan la enfermedad retiniana y el compromiso odontológico.

Dentro de estos criterios menores, se ha propuesto incluir el estudio histopatológico, considerando su utilidad para confirmar el diagnóstico?.

En nuestra paciente y en la madre de ésta, el diagnóstico de IP fue realizado en base al aspecto clínico característico de las lesiones cutáneas. El nuestro sería un caso relatado con poca frecuencia, ya que la mayoría de los reportes publicados se basan en casos esporádicos de la mutación ${ }^{7}$.

En cuanto al pronóstico, éste está determinado por el compromiso ocular y del SNC. Las lesiones cutáneas evolucionan favorablemente a la resolución espontánea, por lo que su tratamiento no es necesario. Sin embargo, cuando los síntomas son muy intensos pueden ser utilizados corticoides o inmunomoduladores tópicos, por períodos cortos.

\section{Conclusiones}

La IP es un trastorno poco frecuente, y en la mayoría de los casos no afecta el desarrollo normal o expectativas de vida del paciente que la padece. Sin embargo, siempre es necesario el estudio multidisciplinario precoz de todos los casos y el control periódico, ya que cabe la posibilidad de un compromiso extracutáneo severo, como el neurológico y/o oftálmico, los que pueden disminuir considerablemente la calidad de vida del paciente. Además, por tratarse de una enfermedad hereditaria, es indispensable realizar una historia familiar detallada y consejo genético.

\section{Referencias}

1.- Landy SJ, Donnai D: Incontinentia pigmenti (BlochSulzberger syndrome). J Med Genet 1993; 30: 53-9.

2.- Makris C, Godfrey VL, Krähn-Senftleben $G$, et al: Female mice heterozygous for IKK gamma/NEMO deficiencies develop a dermatopathy similar to the human X-linked disorder incontinentia pigmenti. Mol Cell 2000; 5 (6): 969-79.

3.- Buinauskaite E, Buinauskiene J, Kucinskiene V, Strazdiene $D$, Valiukeviciene $S$ : Incontinentia pigmenti in a male infant with Klinefelter syndrome: a case report and review of the literature. Pediatr Dermatol 2010; 27 (5): 492-5. doi: 10.1111/j.1525-1470.2010.01261.x. Epub 2010 Aug 27.

4.- Kenwrick S, Woffendin H, Jakins T, et al: Survival of male patients with incontinentia pigmenti carrying a lethal mutation can be explained by somatic mosaicism or Klinefelter syndrome. Am J Hum Genet 2001; 69 (6): 1210-7.

5.- Franco LM: Incontinentia pigmenti in a boy with XXY mosaicism detected by fluorescence in situ hybridization. J Am Acad Dermatol 2006; 55: 136-8.

6.- Berlin AL, Paller AS, Chan LS: Incontinentia pigmenti: a review and updateon the molecular basis of pathophysiology. J Am Acad Dermatol 2002; 47: 169-90.

7.- Fryssira H, Kakourou T, Valari M, Stefanaki K, Amenta $S$, Kanavakis E: Incontinentia pigmenti revisited. A novel nonsense mutation of the IKBKG gene. Acta Paediatr 2011; 100 (1): 128-33. doi: 10.1111/j.1651-2227. 2010.01921.x.

8.- Carney RG: Incontinentia pigmenti. A world statistical analysis. Arch Dermatol 1976; 112: 535-42.

9.- Hadj-Rabia S, Rimella A, Smahi A, et al: Clinical and histologic features of incontinentia pigmenti in adults with nuclear factor- $\kappa \mathrm{B}$ essential modulator gene mutations. J Am Acad Dermatol 2011; 64 (3): 508-15. Epub 2011 Jan 20.

10.- Adeniran A, Townsend PL, Peachey RD: Incontinentia pigmenti (Bloch- Sulzberger syndrome) manifesting as 
ENEI L. y cols.

painful periungual and subungual tumors. J Hand Surg 1993; 18: 667-9.

11.- Francois $J$ : Incontinentia pigmenti (Bloch-Sulzberger syndrome) and retinal changes. Br J Ophthalmol 1984; 68: 19-25.

12.- O'Doherty M, Mc Creery K, Green AJ, Tuwir I, Brosnahan D: Incontinentia pigmenti-ophthalmological observation of a series of cases and review of the literature. Br J Ophthalmol 2011; 95 (1): 11-6.

13.- Domínguez-Reyes A, Aznar-Martin T, Cabrera-Suarea $E$ : General and dental characteristics of Bloch-Sulzberger syndrome. Review of literature and presentation of a case report. Med Oral 2002; 7: 293-7.

14.- El Fekih L, Hmaied W, Souissi K, Nasri H, Derbel F, Hamdi A: Incontinentia pigmenti: a rare cause of retinal vasculitis in children. La Tunisie medicale 2008; 86 (12): 1079-81.

15.- Abe S, Okumura A, Hamano S, et al: Early infantile manifestations of incontinentia pigmenti mimicking acute encephalopathy. Brain Dev 2011; 33 (1): 2834.

16.- Matelzonas T, Ruvertoni M, Reyno S, Pinchak MC: Incontinentia pigmenti. Presentación neonatal. A propósito de un caso clínico. Arch Pediatr Urug 2010; 81 (1). 